\title{
CORRIGENDUM
}

\section{An exploratory qualitative study on relationships between older people and home care workers in South Korea: the view from family carers and service providers - CORRIGENDUM}

\section{YONGHO CHON}

doi:10.1017/So144686X13000950, published online by Cambridge University Press 16 December 2013.

The correct affiliation for the author is:

Department of Social Welfare, Incheon National University, Incheon, South Korea.

The correct address for correspondence is:

Yongho Chon, Department of Social Welfare, Incheon National University, Incheon, South Korea. E-mail: chamgil@incheon.ac.kr

The correct acknowledgement for this paper should read:

This work was supported by the National Research Foundation of Korea Grant funded by the Korean Government (NRF-201 1-330-Boo142). This work is a revised version of part of the author's doctoral dissertation.

\section{REFERENGE}

Yongho Chon. An exploratory qualitative study on relationships between older people and home care workers in South Korea: the view from family carers and service providers. Ageing and Society, published by Cambridge University Press 16 December 2013. doi:10.1017/So144686X1300095o. 